\title{
$\therefore$ Emergency Contraceptives: A Response from Nurses
}

\section{IJCRR} \\ Section: Healthcare \\ Sci. Journal Impact \\ Factor: 6.1 (2018) \\ ICV: 90.90 (2018) \\ (c) (i) (8) \\ Copyright@IJCRR
}

\section{Seema Jain ${ }^{1}$, Komal Anand ${ }^{2}$}

'Professor, Department of Community Medicine, LLRM Medical College, Meerut, Uttar Pradesh, India; ']unior Resident, Department of Community Medicine, LLRM Medical College, Meerut, Uttar Pradesh, India.

\section{ABSTRACT}

Background: Emergency contraception (EC) is defined as the use of a drug or device to prevent pregnancy after unprotected sexual intercourse and thus can reduce unwanted pregnancy and unsafe abortions. EC is used after the unprotected sex, unlike other regular methods of contraception which are taken before the sexual act. Appropriate knowledge of EC among health care professionals is required as EC are the only method that can be used to prevent pregnancy after unprotected sex or contraceptive accident.

Aims and Objectives: To assess knowledge, attitude and practices regarding emergency contraceptive pills among Nursing students.

Methodology: A cross-sectional study was conducted on Nursing students. Nursing students of all four years who were present and given consent on the day of data collection were recruited for the study. A pre-designed pre-tested self-administered questionnaire was used to assess the knowledge and attitude practices regarding emergency contraceptives among nursing students. Data thus collected were analyzed using appropriate statistical methods.

Results: Out of a total of 297 nursing students who participated, $90 \%$ have heard about emergency contraceptives. Very few were aware of the various methods available for emergency contraception. Only $35.4 \%$ knew about the correct timings of their use. The majority had the misconception that EC can be used to induce abortion and as a birth control measure. $67.4 \%$ showed a favourable attitude towards advising a woman to use EC when needed. $24.8 \%$ said that EC was advised by them to patients or relatives.

Conclusion: Although the awareness about emergency contraceptives is high but the knowledge regarding correct timings and usage is poor.

Key Words: Emergency contraceptives, Levonorgestrel pills, Nursing students, Unwanted pregnancies

\section{INTRODUCTION}

Unwanted, unintended and unplanned pregnancies pose a major challenge to the reproductive health of young females. ${ }^{1}$ Emergency Contraceptiveshave comes up as a revolutionary method to control the unwanted pregnancies. Worldwide unplanned pregnancy is a major medical, social, and public health problem. There are 80 million unplanned pregnancies in the world every year, of which $38 \%$ of all pregnancies can be deemed as an epidemic. The WHO estimates that about 46 million abortions are performed under unsafe conditions. There is growing worldwide acceptance and promotion of $\mathrm{EC}$ as a measure to reduce the level of unwanted pregnancies and, hence, unsafe abortion. ${ }^{2}$ As stated by WHO Worldwide nearly 210 million pregnancies occur annually, of which $38 \%$ are unwanted pregnancies and nearly $22 \%$ pregnancies end with abortion. ${ }^{2}$

Incidence of induced abortion in India is about 12 million and maternal mortality due to unsafe abortion is about $13 \%$. Most of the induced abortion is due to unwanted pregnancy. ${ }^{3}$ Emergency contraception is a safe and extremely effective method to reduce the rate of unintended pregnancies, induced abortion and unwanted childbirth. Despite being introduced in National Family Welfare Programme in 2003 and later declared as an OTC (over the counter) products in 2005

\section{Corresponding Author:}

Dr. Seema Jain, Professor, Department of Community Medicine, LLRM Medical College, Meerut, Uttar Pradesh, India. E-mail: drseemajain11@gmail.com

ISSN: 2231-2196 (Print)

Received: 13.06 .2020
ISSN: $0975-5241$ (Online)

Revised: 23.08 .2020
Accepted: 09.10 .2020
Published: 12.11 .2020 
it remains a grossly underutilized option in the prevention of pregnancy ${ }^{3}$ The best way to prevent unintended or unwanted pregnancy is to consult a family planning provider before or immediately after the sexual act, but young women and adolescents might be due to the fear don't consult properly leading to increased cases of unintended pregnancy making it an important concern. ${ }^{1}$

Drug Controller of India has approved Levonorgestrel only regimen to be used as a "dedicated product" for emergency contraception which id manufactured and marketed as a specially packaged two-pill pack, each pill containing $0.75 \mathrm{mg}$ levonorgestrel, available at a reasonable cost on medical prescription. Government of India have attempted by providing the EC pill free of cost through its network of family welfare clinics. ECS are cost-effective, medically safe, and highly effective to be used for the prevention of unplanned pregnancy and subsequently avoid unsafe abortion and other consequences. ${ }^{4}$

Nursing personnel are an integral part of any health care system. They act as a reliable source of information for the general public who are exposed to them. The knowledge and attitude of nursing personnel towards contraception can grossly influence the contraceptive practices of the community as they act as both health educators and service providers. Lack of awareness, misconceptions and negative attitude towards EC in nursing personnel can both act as a barrier for their personal use and also prevent them from promoting EC to the beneficiaries. Very few studies have been done in our country in this area. ${ }^{5}$

So to explore their knowledge and attitude towards EC, we carried out this study on the nursing students to assess their role as a health provider and health educator as they are the main workforce for patient care in hospitals.

\section{MATERIALS AND METHODS}

A Cross-sectional study was conducted by the Department of Community Medicine, LLRM medical college, Meerut from September 2019 to November 2019 using purposive sampling. The study was conducted in the College of Nursing, SVBP Hospital, Meerut. Data was collected from the nursing students of all four academic years i.e. first year to final year.

Study design: Cross-sectional study

Study location: College of Nursing, SVBP Hospital, Meerut, Uttar Pradesh, India

Study duration: September 2019 to November 2019

Sample size: 297 nursing students

Inclusion criteria: All the nursing students present on the day of data collection and also gave consent were included for the study.
Exclusion criteria: Nursing students not present on the day of data collection and also those who were not willing to participate were excluded from the study.

Procedure methodology: A pre-designed, pre-tested, selfadministered questionnaire was used to collect information. The participants were asked to complete the questionnaire without leaving any un-attempted or incomplete questions. Verbal informed consent was taken from all the participants and they were assured of maintaining strict confidentiality. The study was approved by the institutional ethical committee.

Knowledge level was calculated considering students knowing a minimum of 4 aspects of Emergency Contraceptive measures. Following four aspects were considered:

1. Knowledge about a minimum of $\geq 2$ methods.

2. Knowledge about the proper use of a minimum of $\geq 2$ methods.

3. Knowledge about the condition in which EC can be used.

4. Knowledge regarding side-effects of EC.

On basis of the above aspects students were classified as having various levels of knowledge:

1. Good Knowledge: correctly aware of all 4 aspects

2. Inappropriate Knowledge: correctly aware of $\geq 2 \&<4$ aspects

3. Poor Knowledge: correctly aware of $<2$ aspects.

Statistical analysis: Data obtained were entered and analysed using Epi Info. Descriptive statistics were used and expressed as mean and standard deviation and qualitative variables were expressed in percentages.

\section{RESULT}

A total of 297 nursing students participated in the study. There were 255 female and 42 male nursing students who participated in the study. It was observed that $64.3 \%$ of participants were within the age group of 19-22 years and the overall mean age of the participants was $19.4 \pm 1.726$ years.

Table 1 reveals about the knowledge of Emergency contraceptives among the nursing students. Nearly $90.9 \%$ of the total participants have heard about Emergency contraceptives be it combined oral contraceptive pills or copperbearing IUDs or emergency contraceptive pills containing Levonorgestrel(LNG) or emergency contraceptive pills containing ulipristal acetate. On assessing the awareness regarding various methods being used as emergency contraceptives it was seen that although the majority were aware of OCPs $(49.5 \%)$ and Emergency contraceptive pills containing Levonorgestrel (LNG) (31.6\%) being used as emergency contraceptives, very few were aware of the fact that IUDs 
(16.2\%), and Emergency contraceptive pills containing ulipristal acetate $(2.7 \%)$ can also be used as a method for emergency contraception.

Overall knowledge regarding the correct time limit for administration and whether they can be used on regular basis (i.e. any of the emergency contraception method should only be used on emergency conditions and not regularly) was very low, being only $35.4 \%$ and $24.2 \%$ respectively. Also, knowledge about Emergency Contraceptives being not protective against HIV or STI's transmission was improper, only $38.4 \%$ had the correct information, as they don't protect against HIV/AIDS or STIs. Also, knowledge regarding various conditions in which a woman can be prescribed emergency contraceptives was assessed and it was seen that although the majority of students were aware of the various conditions like unprotected sexual intercourse, condom breakage/ slippage, Sexual assault, in which emergency contraceptives can be used but the majority had a misconception that these contraceptives can be used for induction of abortion and as a birth control measure.

Nursing students were inquired about the major source of information and it was seen that Doctors/ health care workers or teachers/textbooks were found to be the major source (62\%) followed by mass media including T.V./Radio/newspaper $(25 \%)$ (Figure 1)

Attitude and practices of nursing students who have ever heard about the EC were assessed and it was seen that the majority of nursing students believed that Emergency contraceptives are safe to use. $67.4 \%$ showed a positive attitude regarding advising a woman to use EC when needed. $61.1 \%$ of nursing students believed that emergency contraceptives can result in casual approach towards sex. Nearly $71.1 \%$ believed that emergency contraceptives can discourage the consistent use of condoms which is a major concern as emergency contraceptives are not a measure of birth control and should not be used on regular basis. (Table 2).

Also, practices of nursing students regarding Emergency Contraceptives were analysed and it was seen that 67 nursing students reported that emergency contraceptives were being advised by them to patients or relatives. Among those who were advised emergency contraceptives by the nursing students nearly 35 of them confirm of using them. (Table 2)Study reveals that out of all those who were sexually active only one-third have ever used emergency contraceptives themselves and the majority of them stated of using hormonal pills. Those who were using emergency contraceptive pills, $32 \%$ stated that condom breakage or slippage was the main reason for using emergency contraception measure.

Table 3 reveals the Knowledge status of the study population. Study shows that only $23.6 \%$ have good knowledge, $32.9 \%$ have inappropriate knowledge and $43.4 \%$ have poor knowledge about emergency contraceptives. Hence, it can be seen that until and unless nursing personnel will be having overall good knowledge regarding emergency contraceptives they will not be so sure in advising EC to the general population and will also lack in proper guidance to the one in need.

\section{DISCUSSION}

The awareness regarding emergency contraceptive pills among the students $(90.9 \%)$ is quite similar to that reported by HimanshiGangwalet $a l .^{3}$ among nursing personnel while it is much more than reported by Puri S, Bhatia Vet al among college students in Chandigarh (7.3\%). ${ }^{6}$

Although the knowledge regarding the correct time interval from unprotected sexual intercourse up to which these pills can be taken i.e. 72 hours is very low in the current study (35.4\%) than reported by Priya Arora et al. ${ }^{1}(40 \%)$ while it is much better than that reported by Puri S and Bhatia V et al ${ }^{6}$ $(14.1 \%)$, more than half of these women are not aware of its correct time of use which makes these women more susceptible for the consumption of these pills at the incorrect time and puts them at risk of unwanted pregnancies.

Study reveals that doctors/health care workers/teachers/textbooks $(62 \%)$ was the main source of information followed by mass media/T.V./Radio (25\%) which was almost similar to that reported by HimanshiGangwalet $a l^{3}$ which reported that textbooks $(78 \%)$ were the main source of information about emergency contraception followed by media (14\%) and only $2 \%$ nursing personnel got information from doctors. This shows that the majority gets information about EC either from teachers/textbooks/healthcare workers or from mass media and very few learn about EC from family/relatives. Although the history of education has made sex education and knowledge of contraceptives essential from higher secondary onwards these chapters are often neglected by teachers in school education and the faulty media becomes the main source of information.

In the study, it was observed that only $16.2 \%$ were aware of IUDs as a form of emergency contraceptive which is much lower than that reported by Nivedita.K and Fatima Shanthini et al who reported that nearly $35.67 \%$ were aware of IUD as a form of EC. ${ }^{5} 67.4 \%$ of the women showed a positive attitude towards the use of ECPs which is much more than that reported by Priya Arora et al. where only $38 \%$ students agreed or strongly agreed that they would either themselves use or recommend emergency contraceptive pills in case of need. ${ }^{1}$ Study reveals that only $23.6 \%$ have a good knowledge regarding emergency contraceptives which was much less than that reported by Nivedita and Shanthini (52.43), 32.9\% have inappropriate knowledge and $43.4 \%$ have poor knowledge about emergency contraceptives. ${ }^{5}$ A similar study carried out in Sik- 
kim reported that only $28 \%$ had actual knowledge on EC and $40 \%$ had a positive attitude towards EC. ${ }^{7}$

\section{CONCLUSION}

Nurses with complete knowledge and positive attitude towards EC can act as effective counsellors to the public to create awareness, improve their understanding and change their attitude towards EC. Knowledge combined with a positive attitude is very much essential to improve the dispensing practice of EC. The present study recommends that every nursing and paramedical staff should be informed and educated about Emergency Contraceptives, therefore training programmes to nursing personnel on emergency contraception is mandatory and regular updates are also essential to them regarding various aspects of contraception so that they can act as an effective counsellor to the public to create awareness, improve their understanding and change their attitude towards emergency contraception.

\section{ACKNOWLEDGEMENTS}

Authors would like to acknowledge the principle of SVBP Nursing College, who provided immense help to conduct the study uninterruptedly, Also would like to acknowledge the nursing students who gave their precious time and provided the information needed to conduct the study. Authors also acknowledge the immense help received from the scholars whose articles are cited and included in references.
Conflict of Interest: No Conflict of interest

Financial Support: No Financial Support

\section{REFERENCES}

1. Arora P, Bajpai RC, Srivastava R. Emergency Contraception: A Study to Assess Knowledge, Attitude and Practices among Female College Students in Delhi. Natl J Community Med 2013;4(2):282-285.

2. Mishra M, Tripathi SS, Verma MK. Knowledge and Attitude Towards Emergency Contraception in Females of Urban Area of Lucknow, Uttar Pradesh, India. Int J Reprod Contracept Obstet Gynecol 2017;6(1):210-214.

3. Gangwal H, Benwal D, Mital P, Agarwal S, Anani R. Knowledge, Attitude And Practices About Emergency Contraception Among Hospital Nursing Staff of the Obst\&Gynae Department, SMS Medical College, Jaipur. Sch J App Med Sci 2016;4(9E):3471-3475.

4. Mishore KM, Woldemariam AD, Huluka SA. Emergency Contraceptives: Knowledge and Practice towards Its Use among Ethiopian Female College Graduating Students. Int J Reprod Med. 2019;1-8.

5. Nivedita K; Knowledge, Attitude and Practice of Emergency Contraception on Nursing Personnel. J Clin Diag Res 2014;8(9):OC20-OC22.

6. Puri S, Bhatia V, Swami HM et al. Awareness of emergency contraception among female college students in Chandigarh, India. Indian J Med Sci. 2007;61(6):338-346.

7. Rahaman H, Renjhen P, Kumar A, Pattanshetty S, Sagir A, Dubey H. A study on emergency contraceptive practice among nursing staff in Sikkim, India - A cross-sectional study. AMJ. 2010;3(10):667-71.

Table 1: Knowledge of nursing students about Emergency Contraceptives (Correct response)

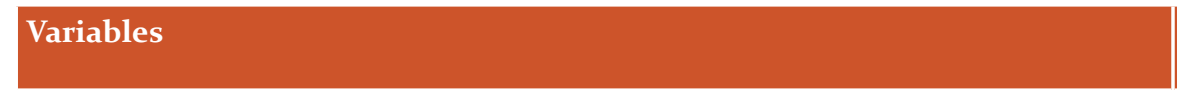

Ever heard about any Emergency Contraceptives (whether OCPs/IUCDs/LNG only pills)?(Yes)

Availability of Emergency contraceptives at government centres? (Available)

Knowledge regarding various methods of Emergency Contraceptives.

a. Combined oral contraceptive pills

b. Copper bearing IUD's

c. ECPs Containing LNG

d. ECPs Containing Ulipristal acetate

Best time to use Emergency Contraceptives (within $72 \mathrm{hr} / 5$ Days of unprotected intercourse).

Knowledge regarding use of Emergency Contraceptives only on Emergency conditions.

EC protect against HIV/AIDS or STIs.(NO)

EC act as an abortifacient. (No)

Knowledge about common side-effects of Emergency Contraceptives. (Nausea, Menstrual Irregularity, Fatigue)

\section{Number ( $\mathrm{N}=297)$} (n)

270

155

52.2 
Table 1: (Continued)

Variables
Number $(\mathrm{N}=297)$

(n)

A woman can use emergency contraceptives for conditions like:

a. Unprotected sexual intercourse

b. Sexual Assault

$229 \quad 77.1$

c. Failure of birth control measure

d. Condom breakage/slippage

e. For induction of abortion

$189 \quad 63.6$

$170 \quad 57.2$

$233 \quad 78.5$

$171 \quad 57.6$

f. As a birth control measure

225

75.8

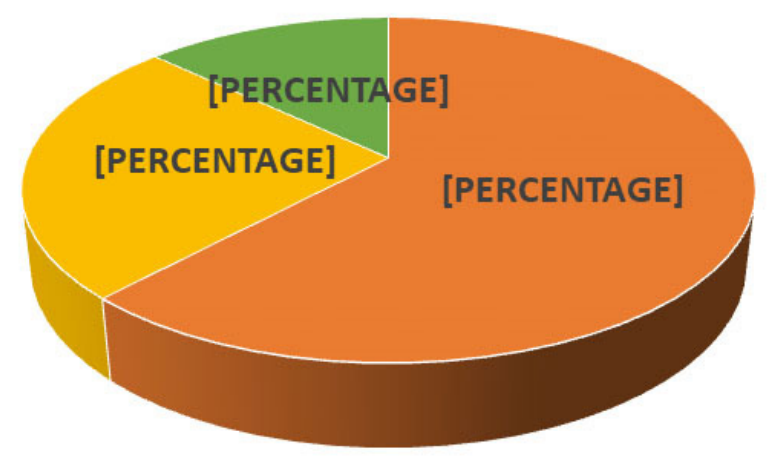

- Doctors/ Health Workers/Teachers/Textbooks = TV/Radio/Newspaper $\quad$ - Friends/Family

Figure 1: Source of Information about Emergency Contraceptives $(n=270)$

Table 2: Attitude and Practices of nursing students regarding Emergency Contraceptives. $(\mathrm{N}=\mathbf{2 7 0})$

\begin{tabular}{lcc} 
Variables & Number & Percentages (\%) \\
Will you advise a woman to use EC when needed. (Yes) & 182 & 67.4 \\
EC may result in casual approach towards sex. (Yes) & 165 & 192 \\
ECPs can discourage the consistent use of condoms. (Yes) & 145 & 71.1 \\
EC are safe for users. (Yes) & 67 & 53.7 \\
Ever advised ECs to patient/relative? (Yes) & 35 & 24.8 \\
Out of those advised, how many of them used (Yes) $(\mathrm{n}=67)$ & 52.2 \\
\hline
\end{tabular}

Table 3: Knowledge status regarding Emergency Contraceptives. $(\mathrm{N}=297)$

\begin{tabular}{l|c|c} 
Variables & $\begin{array}{c}\text { Number } \\
\text { (n) }\end{array}$ & Percentages (\%) \\
Good Knowledge & 70 & 23.6 \\
Inappropriate Knowledge & 98 & 32.9 \\
Poor Knowledge & 129 & 43.4 \\
\hline
\end{tabular}

